\title{
SHAKING TABLE TESTS ON A MODEL
}

\section{RETAINING WALL}

\author{
Lai Cho Sim* and J.B. Berrill*
}

\section{SYNOPSIS}

Shaking table tests of a model gravity retaining wall are described. The tests were designed to check the validity of the simple analytical model of wall behaviour proposed by Elms and Richards in a companion paper. The results show that the wall translates outwards in a stepwise fashion under strong shaking as predicted by the analytical model, and that with one minor exception the assumptions underlying the model appear correct.

\section{INTRODUCTION}

(1) In a companion paper, Elms and Richards (1) present a new method for designing gravity retaining walls. The possibility of large translation of the wall under seismic loading is recognized. Their design procedure, is based upon a simple analytical model (2) which considers the equilibrium of a wall under Mononobe-Okabe earth pressures, resistance of the wall base, and the wall inertia force. This paper describes shaking table tests of a model retaining wall, undertaken to verify the general correctness of the Richards and Elms theoretical model, and to check the validity of its assumptions.

\section{TEST SEMUP}

The tests used a $2.4 \mathrm{~m}$ long glass-sided rectangular tank, $510 \mathrm{~mm}$ wide, mounted on the University of Canterbury $65 \mathrm{kN}$ electrohydraulic shaking table, which has been described elsewhere (3). The shaking table motion could be programmed either by a function generator or by an analogue signal on F.M. tape. Both steady-state sinusoidal table motion and scaled earthquake accelerograms were used. Figure 1 shows an overall view of the test setup.

A $300 \mathrm{~mm}$ high model wall, backfilled to $250 \mathrm{~mm}$ above its base was placed at approximately the two-thirds points of the tank as shown in Figure 2. The depth of soil beneath the wall base was $100 \mathrm{~mm}$ in all tests.

Bending moment, and vertical and horizontal shear forces on the rear face of the model wall were measured by a pair of identical load cells. Outputs from the loadcell strain-gauge bridges were amplified by a dynamic strain amplifier and recorded on a multi-channel highspeed chart recorder. Other instrumentation included a pair of displacement transducers to record displacements of the top and of the base of the wall relative to the tank, and two accelerometers measuring the tank (ground) motion, and the motion of the wall base. These, too, were recorded on the chart recorder. Further details of the instrumentation may be found

* Department of Civil Engineering, University of Canterbury, Christchurch. in the senior author's report ${ }^{(4)}$.

Brighton Beach sand was used in all tests. It is a fairly uniform fine-to-medium sand with an angle of internal friction, measured by direct shear tests, of about 30 degrees.

Seals between the model wall and the plate-glass sides of the tank, separated by a gap of $2 \mathrm{~mm}$, were made with two layers of P.V.C. insulating tape stuck to the model wall and then back-to-back to form a fairly stiff skirt which trailed against the glass. These seals also served to keep the model wall aligned correctiy.

Finally, since wall weight is an important parameter in the theoretical model, provision was made to add masses to the model in the form of steel plates bolted to the wall base. The resulting low centre of gravity ensured translational rather than rotational, motion of the wall.

\section{SHAKING TABLE TESTS}

The series of tests carried out can be divided as follows into three classes, depending on the type of excitation used and whether or not it was strong enough to cause yielding of the backfill and corresponding relative displacement of the wall model.

Class 1. Periodic excitation, no yielding, at $2.5,5.0,10$ and $15 \mathrm{~Hz}$ and acceleration amplitudes of $0.05 \mathrm{~g}, 0.10 \mathrm{~g}, \ldots$ until yielding was imminent.

Class 2. Periodic, $5 \mathrm{~Hz}$ excitation with an acceleration amplitude of $0.44 \mathrm{~g}$, sufficient to cause wall translation.

Class 3. Scaled El Centro, 1940, N-S and 1966, Parkfield, California, array No. 2 horizontal accelerogram component.

The tests were repeated with a number of different wall weights. Results from the Class 1 tests principally gave information about dynamic soil pressures; Class 2 and Class 3 tests checked the general validity of the analytical model, examined yielding thresholds, and checked the kinematic assumptions of the Richards and Elms model. 


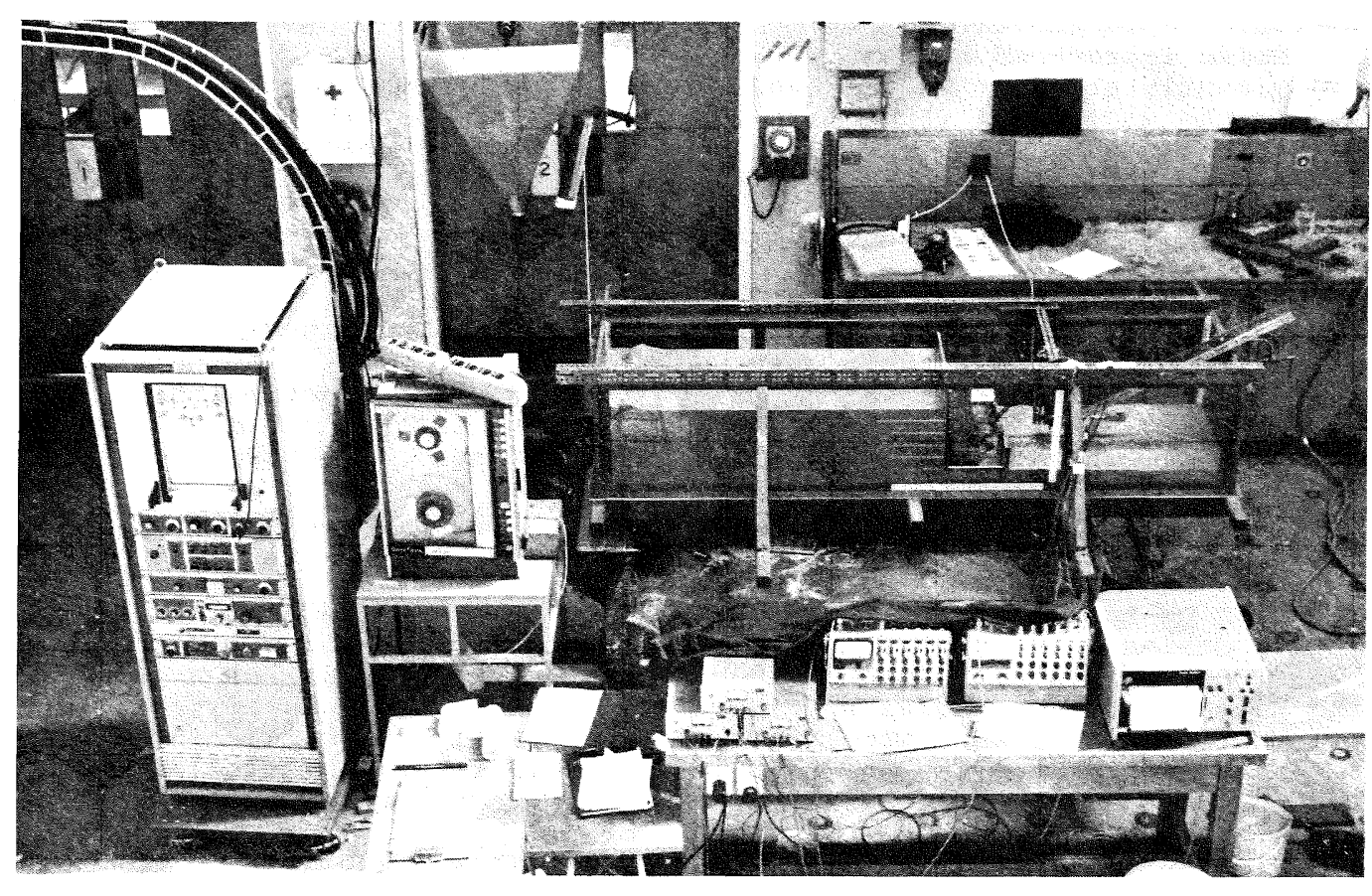

FIGURE 1: VIEW OF TEST SET UP

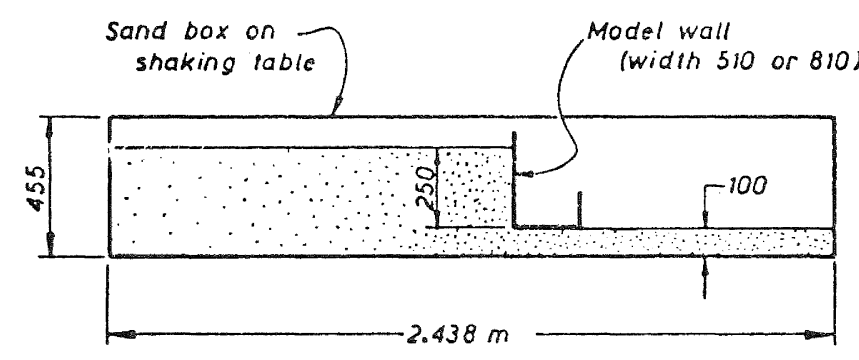

\section{- TEST SETUP-}

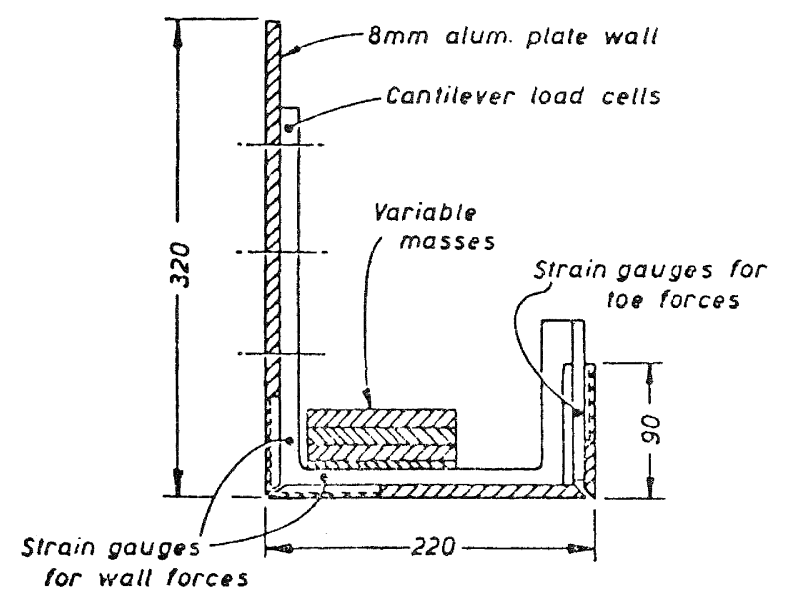

\section{- DETAILS OF MODEL WALL-}

FIGURE 2: LONGITUDINAL CROSS-SECTION OF SAND TANK AND DETAILS OF MODEL WALL. 
The periodic table excitation was nearly sinusoidal. Noise introduced by the control system, predominantly at about $100 \mathrm{~Hz}$, and superimposed on the sinusoidal input signal was marked in the table acceleration trace. However, because of its high frequency there was little evidence of noise in the table displacements. Since the Richards and Elms theoretical model assumes an arbitrary, rather than harmonic, input, this did not pose any problem. With the scaled accelerograms, the presence of system noise meant that in order to compare observed wall behaviour with that computed from the theoretical model it was necessary to digitize the actual table acceleration and to use that as input to the analytical model.

The accelerogram traces were scaled to have acceleration peaks close to their actual values and time scales were compressed to one-fifth their natural value. Since the Richards and Elms theoretical model should apply equally well to small and large walls, the experiments could be regarded as fullsized tests on a small wall, thereby avoiding difficult scaling problems.

\section{RESULTS: OVERALL BEHAVIOUR}

The practical purpose of the simple theoretical model is to predict gross wall displacements relative to the surrounding countryside during strong ground shaking. It is based on fairly sweeping simplifying assumptions and does not pretend to model details of the wall motion exactly. Thus the first objective of these experiments was to check whether the overall behaviour of the wall was at all close to that predicted by the analysis. The results showed a remarkable similarity in displacements and certainly validate the general approach of the analytical model. Figure 3 compares observed and computed displacements of a wall with a threshold acceleration of $0.11 \mathrm{~g}$ under the 1966 Parkfield, California record. While the amounts of displacement differ, their shapes are quite similar. In particular, in each trace, the ratios of the two large displacement steps are identical. Examining the Parkfield accelerogram in Figure 4, it is seen that the wall displacement is caused by the two acceleration peaks at 0.4 and 0.6 seconds.

Under the more complicated El centro, 1940, N-S component, the similarity in shape of the observed and predicted displacement curves is still reasonably good, though not as good as in the Parkfield case. Figure 5 shows a comparison for three different wall weights (i.e. for three different threshold accelerations), Figure 6 shows the corresponding accelerogram. The general similarity in predicted and measured displacement is clear. The Richards and Elms theory overpredicts the total displacements and is therefore conservative as it stands. However, in each case, geometric similarity of the displacement traces is not closely preserved in detail; the rate of divergence of the traces appears to be greater in the latter stages of shaking than in the early stages. This is partly due to a decrease in the backfill level as the wall displaces, an effect which was not accounted for in the analytical model. Also, the smaller total displacement of the physical model may be caused by an increase in base friction. This possibility is discussed further in ref. (4).

The important conclusion from this section is that the simple Richards and Elms model describes the overall mechanics of the problem very well. Furthermore, it appears that with only minor changes in detail, it is also capable of predicting wall displacements accurately.

\section{RESULTS: ASSUMPTIONS OF MODEL}

In this section the main assumptions of the theoretical model are checked against the observed behaviour of the physical model.

The principal assumptions of the model are:

1. That the wall starts to slide relative to the surrounding soil when the ground acceleration reaches a threshold value.

2. Wall acceleration then remains constant until relative motion of wall and soil ceases according to assumption 4 .

3. That the threshold ground acceleration value can be obtained by considering the limiting equilibrium of the wall under base friction and active earth pressure given by the Mononobe-Okabe expressions.

4. That relative motion ceases when wall and ground velocities are again equal.

\subsection{Assumption 1}

Figure 7 shows a plot of wall acceleration amplitude vs table acceleration amplitude for three different wall weights. Within the limits of the density of data points, and their scatter, the constant-threshold assumption appears reasonable.

\subsection{Assumption 2}

The assumption that once relative motion has commenced wall acceleration remains constant, is clearly not fulfilled. Nevertheless, while not constant above the threshold level, wall acceleration does vary in a reasonably linear manner with table acceleration, suggesting a simple modification to the theoretical model.

\subsection{Assumption 3}

Assumption 3 can be checked by comparing observed. threshold values with those predicted by the theoretical model (equations 3.7 or 3.8 (reference 2). The theoretical threshold value is a function of the wall mass, the wall and soil geometry and the soil properties. In estimating the theoretical threshold of the model wall, only the soil properties offer any uncertainty. of the four soil parameter values required by the model, the angle of internal function, $\phi$, the angle of sand-to-wall friction, $\delta$, and the sand density, $\rho$, could be measured quite precisely $(4)$ and they appeared to remain stable throughout the tests. However, the angle of base friction between the aluminium model and the sand could not be found with such confidence. In separate tests ${ }^{(4)}$ it appeared to be near 20 to 22 degrees during the initial stages of relative motion.

Figure 8 shows computed and observed 


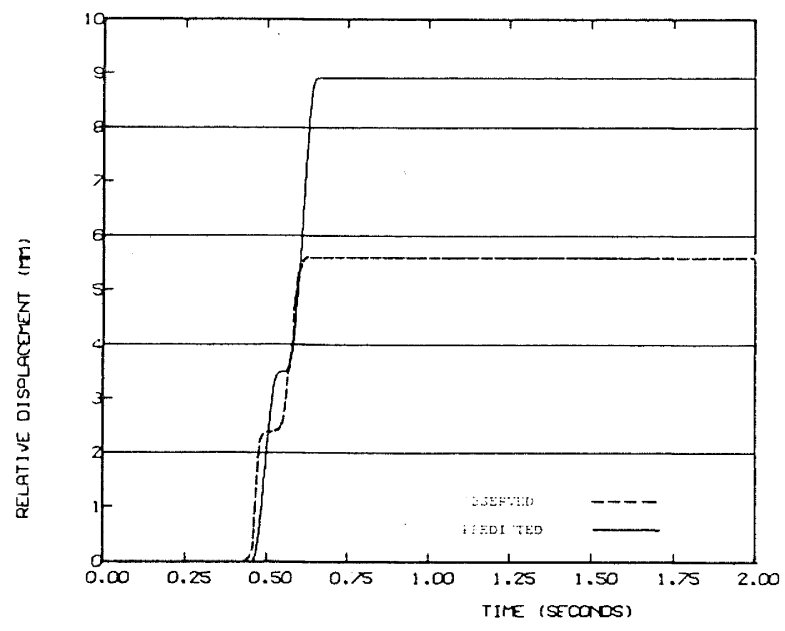

FIGURE 3: COMPARISON OF RELATIVE WALL DISPLACEMENTS UNDER LY SCALED 1966 PARKFIELD, CALIF. MOTION.

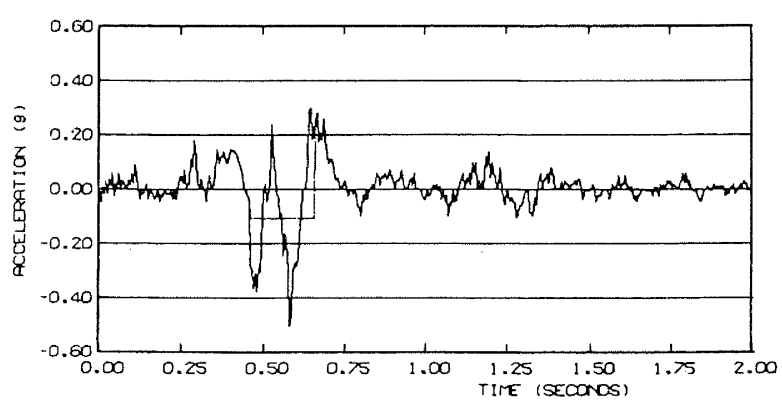

FIGURE 4: TABLE ACCELERATION UNDER PARKFIELD EXCITATION. DOTTED LINE SHOWS WALL ACCELERATION ASSUMED IN THEORETICAL MODEL.

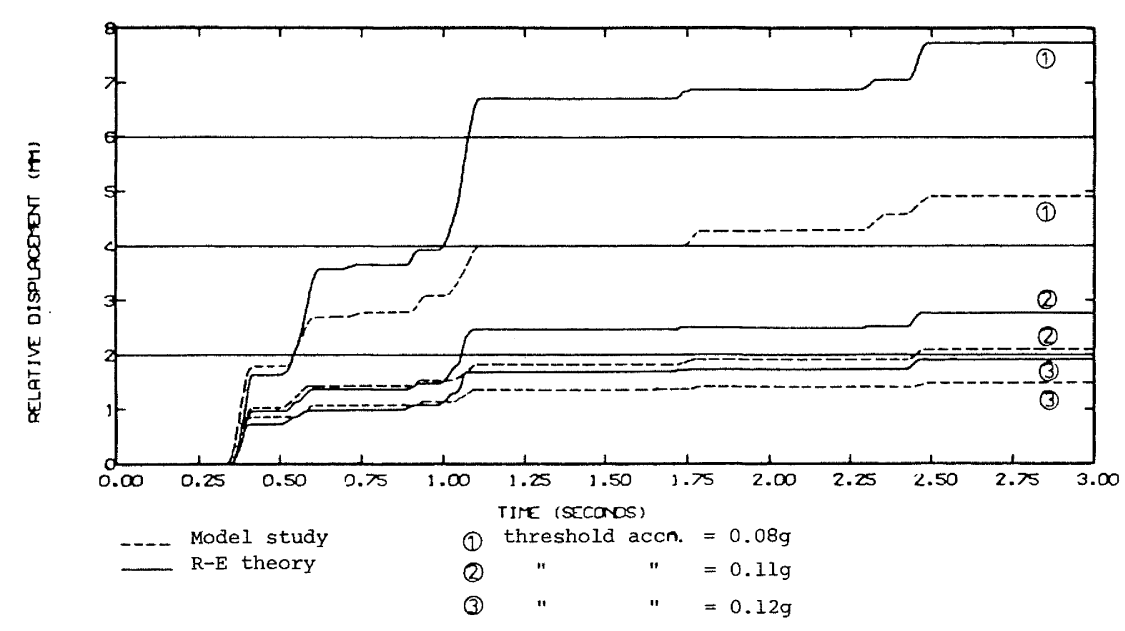

FIGURE 5: COMPARISON OF RELATIVE WALL DISPLACEMENTS UNDER SCALED 1940 EL CENTRO N-S MOTION.

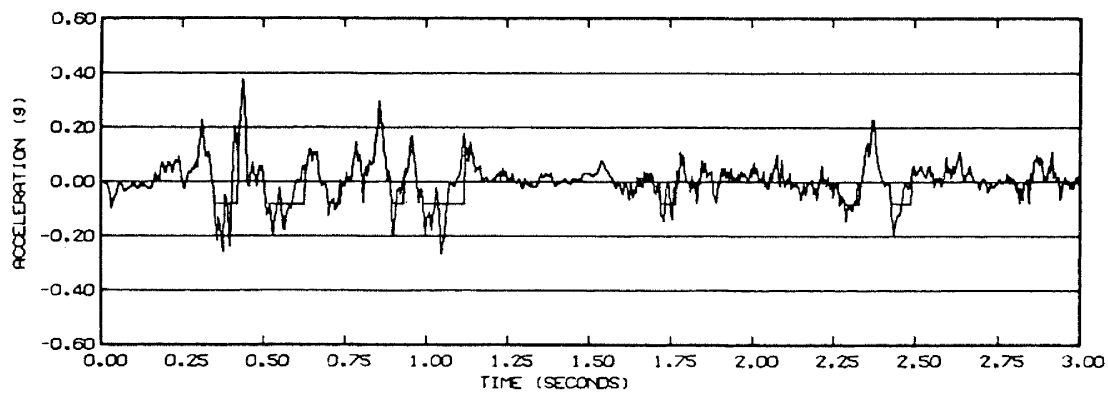

FIGURE 6: SCALED 1940 EL CENTRO, CALIF. N-S TABLE ACCELERATION CORRESPONDING TO DISPLACEMENT RECORDS IN FIGURE $5.0 .08 \mathrm{~g}$ THRESHOLD ACCELERATION ALSO SHOWN. 
threshold accelerations plotted against wall mass. For a given wall mass, the observed thresholds values are a little higher than expected; but they are certainly close to the estimated values, given the uncertainty of the value of base friction and the sensitivity of the threshold values to it.

\section{4 Assumption 4}

From a rough, preliminary integration of acceleration traces it appears that assumption 4 is followed quite closely. However, further work is required to confirm this.

\section{CONCLUSIONS}

The tests described in this paper confirm the importance of the wall inertia force in the behaviour of gravity retaining walls during earthquakes.

The tests also show that the general behaviour of a gravity wall is described remarkably well by the simple Richards and Elms theoretical model. Furthermore, with one exception, it appears that the detailed assumptions of the model are correct. The assumed constant post-yield acceleration was not seen in the laboratory tests, but the linear relationship observed between ground and wall accelerations should be easily incorporated into the model.

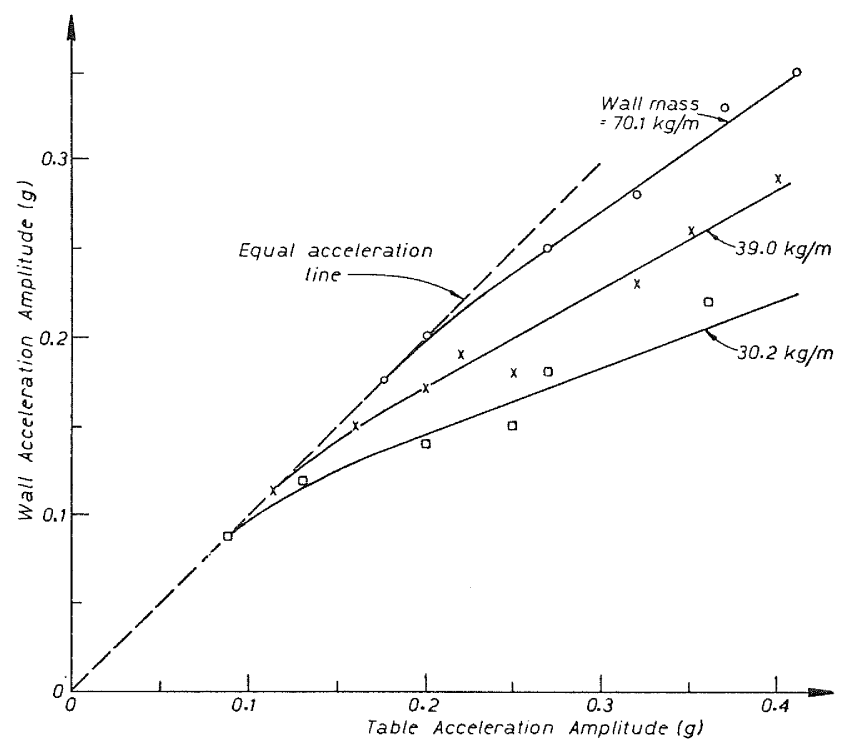

FIGURE 7: WALL ACCELERATION AMPLITUDE VS TABLE ACCELERATION AMPLITUDE. DATE BELOW THRESHOLD LEVELS LAY ON THE EQUAL ACCELERATION LINE

\section{ACKNOWLEDGEMENTS}

The authors wish to thank R. O. Davis, D. G. Elms and M. J. N. Priestley for many helpful discussions. The financial support of the New Zealand National Roads Board, Grant No.4766, and the University of Canterbury through a Research Assistants grant, is gratefully acknowledged.

\section{BIBLIOGRAPHY}

1. Elms, D. G. and Richards, R., "Seismic Design of Gravity Retaining walls", Bulletin of the N.Z. National Society for Earthquake Engineering, Vol. 12, No. 2, June 1979.

2. Richards, R. and Elms, D. G., "Seismic Behaviour of Retaining Walls and Bridge Abutments", Report No. 77-10, Dept. of Civil Eng., University of Canterbury, 1977.

3. Wilby, G. K., "Response of Concrete Structures to Seismic lotions", Report 75-11, Dept, of Civil Eng., University of Canterbury, 1975.

4. Lai Cho Sim, "Behaviour of Retaining

Walls Under Seismic Loading", Report 79/9, Dept. of Civil Eng., University of Canterbury, 1979.

This paper was presented at the South Pacific Regional Conference on Earthquake Engineering held in Wellington on 8,9 and 10 May, 1979.

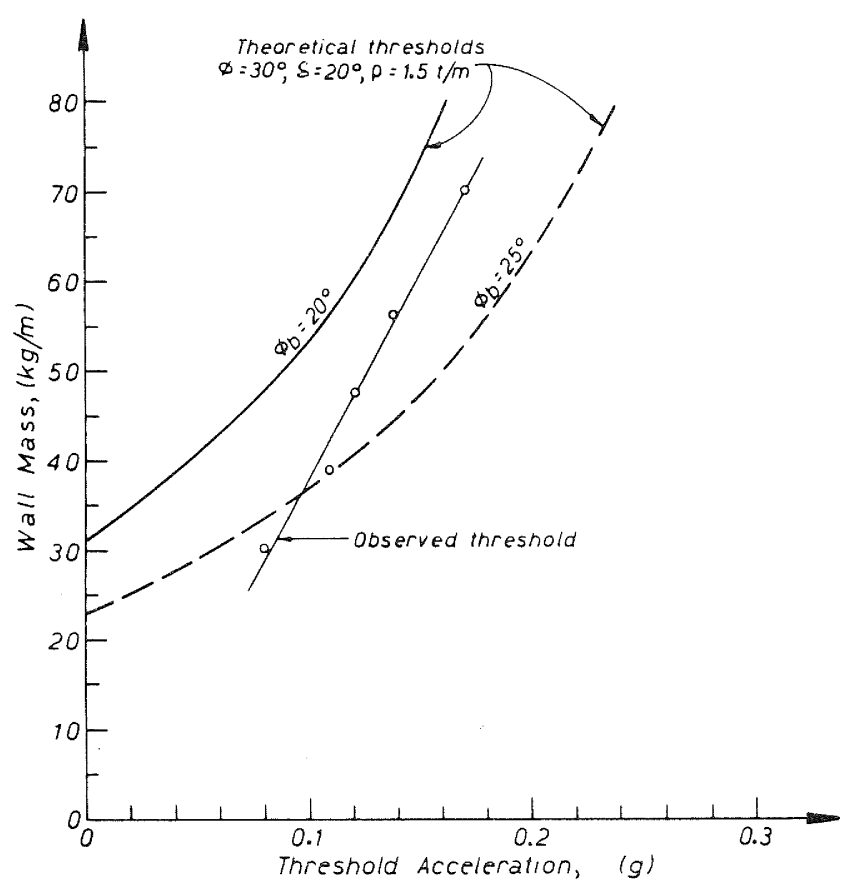

FIGURE 8: COMPARISON OF COMPUTED AND OBSERVED THRESHOLD ACCELERATIONS 